\title{
Trabalho interprofissional em fóruns: Sua importância nos casos de adoção
}

\author{
Interprofessional work in courts: Its importance in adoption cases
}

Vanessa Brandalise Tibolaa ${ }^{[a]}$, Verônica Suzuki Kemmelmeier ${ }^{[b]}$

${ }^{[a]}$ Discente de Psicologia, Universidade Estadual do Centro-Oeste (Unicentro), Cascavel, PR - Brasil, e-mail: vanessa_tbh@hotmail.com

${ }^{[b]}$ Docente do Departamento de Psicologia, Universidade Estadual do Centro-Oeste (Unicentro), mestre em Psicologia da Infância e Adolescência, Universidade Federal do Paraná (UFPR), Irati, PR - Brasil.

Recebido: 09/09/2010 Received: 09/09/2010

Aprovado: 05/04/2011 Approved: 04/05/2011

\section{Resumo}

A adoção é um tema muito referenciado na atualidade em vários âmbitos, porém as equipes interdisciplinares são somente citadas e há poucos estudos específicos sobre este tema. Diante da importância do trabalho desenvolvido pelas equipes, este estudo foi realizado no intuito de esclarecer como é o trabalho das equipes na Vara da Infância e da Juventude de três Fóruns de cidades de médio porte do Estado do Paraná bem como sua importância. Esta pesquisa qualitativa utilizou-se da entrevista semiestruturada e de um questionário de formação acadêmico profissional para realizar o levantamento dos dados. Estes foram submetidos a uma análise de conteúdo e após algumas leituras chegou-se a três grandes tópicos contendo as principais categorias definidas: desenvolvimento do trabalho em equipe; funcionamento do trabalho em equipe e percepções do trabalho em equipe. Conclui-se que, além de ser de extrema importância a composição desta equipe que é formada por Psicólogos e Assistentes Sociais, o relacionamento interno e a estruturação do trabalho fazem a diferença no processo de adoção.

Palavras-chave: Adoção. Vara da Infância e da Juventude. Equipe interprofissional.

\begin{abstract}
Adoption is a much mentioned subject in several areas in present days, but the interdisciplinary teams are only cited and there are few specific studies on this topic. Based on the importance of the work developed by those teams, this study was carried out in order to make clear the work of the teams in the Court for Childhood and Youth (Vara da Infância e da Juventude) of three courts of midsize cities in the state of Paraná as well as their importance. This qualitative research used semi-structured interview and an academic professional training questionnaire to conduct the data collection. These were submitted to content analysis and after some reading we came up with three major topics containing the main categories defined: Teamwork Development; Teamwork Operation and Teamwork Perceptions. We concluded that besides being extremely important the composition of this team, which is made up of psychologists and social workers, the internal relationships and the work structure makes a difference in the adoption process.
\end{abstract}

Keywords: Adoption. Court for Childhood and youth. Interprofessional team. 


\section{Introdução}

A adoção é um tema muito referenciado na atualidade e de grande importância não só para as crianças e adolescentes que esperam pelo momento da adoção, como também para os pais da fila de espera e os profissionais atuantes nas Varas da Infância e da Juventude e nos Serviços de Auxílio à Infância, que muitas vezes se envolvem diretamente nos processos. Segundo Wald (1988), a adoção pode ser definida como uma ficção jurídica que cria um parentesco civil; uma ligação entre pessoas onde a relação parental natural inexiste; um ato jurídico que é realizado com a permissão da lei em virtude da vontade de sujeitos, que cria relações iguais à filiação legítima entre pessoas estranhas. Esse processo adotivo não possui uma data definida de início, mas é referenciado em vários momentos da história.

De acordo com Bandeira (2001), a adoção, na antiguidade, sempre esteve relacionada à necessidade de se manter o culto familiar aos ancestrais. Alguns estudiosos apontam que a adoção pode ter surgido da necessidade, entre os povos mais antigos, de perpetuar as tradições familiares, caso contrário a família que não tivesse filhos estaria fadada à extinção.

Em se tratando de Brasil, de acordo com o autor supracitado, a adoção era um reflexo do Direito Português já que o país era governado sob as leis, regimentos e resoluções de Portugal. Com a independência do Brasil, em 1822, é instituído o direito civil brasileiro no qual os procedimentos para a adoção eram similares aos de hoje: o adotante fazia o pedido ao juiz de primeira instância e após algumas audiências era dada a sentença e a carta de confirmação. Com as alterações feitas no Código Civil, muitas mudanças no processo de adoção também ocorreram. Bandeira (2001) aponta principalmente a mudança no fato de o adotante necessariamente ter 50 anos ou mais, reduzido posteriormente para 30 anos, e não poder possuir nenhum filho legítimo. Outros fatores do Código eram a adoção plena só ocorrer após o estágio de convivência com duração de um ano, o adotando ter necessariamente sete anos de idade e só poderia requerer a adoção os casais com mais de cinco anos de casados.

Ferreira (2008) aponta que, antes de vigorar o Estatuto da Criança e do Adolescente, os procedimentos de habilitação e adoção eram realizados a partir de avaliações. Essas avaliações eram questionários sem qualquer aprofundamento ou análise das questões realizadas e eram efetivadas pelos chamados comissários de menores, formados por pessoas leigas, oficiais de justiça, voluntários, sem a necessidade de uma qualificação técnica adequada a esse procedimento.

Com a aprovação da Constituição Federal de 1988, Paiva (2004) comenta que mais modificações são feitas, como o estabelecimento da igualdade entre os filhos de qualquer natureza e a regulamentação do Estatuto da Criança e do Adolescente (ECA) pela Lei n. 8.069, de 13 de julho de 1990. 0 Estatuto da Criança e do Adolescente (Brasil, 1990) possui como principais pontos a adoção por maiores de 18 anos, independente de estado civil e exige uma diferença de 16 anos entre o adotado e o adotante. Bandeira (2001) complementa que é necessário o consentimento dos pais biológicos para se realizar a adoção, sendo a autorização desnecessária quando os pais biológicos forem falecidos, desconhecidos ou tenham sido destituídos de poder familiar, definido pelo autor supracitado como a retirada dos direitos que esses pais possuem sobre a criança. 0 adotante, quando maior de 12 anos, deve ser ouvido no momento da adoção e ter sua posição aceita.

Schweitzer (2009) publica que, para adotar uma criança, o processo não é burocrático, sendo necessária uma prévia habilitação, como exigida pelo artigo 50 do ECA:

Artigo 50 - A autoridade judiciária manterá, em cada comarca ou foro regional, um registro de crianças e adolescentes em condições de serem adotados e outro de pessoas interessadas na adoção.

$\S 1^{\circ}$ - 0 deferimento da inscrição dar-se-á após prévia consulta aos órgãos técnicos do juizado, ouvido o Ministério Público.

$\S 2^{\circ}$ - Não será deferida a inscrição se o interessado não satisfizer os requisitos legais, ou verificada qualquer das hipóteses previstas no artigo 29 (quando o pretendente apresentar incompatibilidade com a natureza da medida pleiteada ou não oferecer ambiente familiar adequado, deverá ser indeferido o pedido de colocação em família substituta) (Brasil, 1990, p. 18-19).

Assim, avaliam-se os reais motivos do casal ou pretendente para adoção uma vez que esta, segundo Bandeira (2001), é irrevogável. Nessa fase, são realizados os estudos psicossociais e sociais pelas psicólogas e assistentes sociais, respectivamente, e após o 
casal passar por uma etapa de entrevistas e visitas são declarados aptos e são incluídos no cadastro de pessoas habilitadas para adotar (Schweitzer, 2009). Contudo a demora, para o casal ser chamado para conhecer uma criança e possivelmente adotá-la, dependerá das características da criança definidas pelo casal no processo de habilitação. Schweitzer (2009) comenta que muitas vezes os casais fazem muitas exigências quanto ao sexo, idade, cor de pele da criança que idealmente sonham em adotar.

Como citado, este trabalho de entrevistas, estudos e visitas é realizado por psicólogos e assistentes sociais que integram a equipe interprofissional da Vara da Infância e da Juventude, mais especificamente o Serviço Auxiliar da Infância (SAI), este com o objetivo, segundo Silva (2003), de prestar atendimento de orientação às pessoas que buscam o Judiciário e auxiliar o juiz nas questões relacionadas aos processos de adoção e outras questões judiciais. Essa equipe é composta de acordo com a determinação do Poder Judiciário conforme prevê o ECA:

Art. 150 - Cabe ao Poder Judiciário, na elaboração de sua proposta orçamentária, prever recursos para manutenção de equipe interprofissional, destinada a assessorar a justiça da infância e da juventude (Brasil, 1990, p. 48).

Cabe, neste contexto, especificar o porquê de equipe interprofissional e não multiprofissional antes de continuar a explicação do trabalho. Primeiramente, o sufixo "profissional" é utilizado, pois corresponde a práticas concretas e não epistemológicas como no caso do sufixo "disciplinar", diferencia Furtado (2007). Assim, em poucas palavras, o sufixo "disciplinar" será sempre relativo ao campo dos saberes, e "profissional" ao das equipes e seus serviços (Furtado, 2007). Esse mesmo autor aponta que o trabalho multiprofissional é quando vários profissionais atuam em prol de um mesmo benefício, porém sem o trabalho conjunto. Já o interprofissional surge como resposta "à necessidade de reagrupamento de conhecimentos espalhados, como forma de diminuir a alienação do trabalhador" (Furtado, 2007, p. 246). Assim, o trabalho é desenvolvido por mais de um profissional e, em conjunto, atuando em um mesmo trabalho.

Como integrante da equipe, o Psicólogo possui como função interpretar a comunicação e a interação familiar em processos que envolvem modificação de guarda, perda ou suspensão de pátrio poder, casos de adoção, emancipação, tutela e outros.
Outro integrante, o assistente social, mostrará uma visão menos idealizada da adoção ao casal em uma primeira entrevista e irá levantar as expectativas deste. Assim, a assistência social irá criar na Comarca um cadastramento local de crianças e adolescentes disponíveis para adoção bem como uma lista dos casais pretendentes (Silva, 2003).

De acordo com o Manual de Capacitação para Psicólogos e Assistentes Sociais do Poder Judiciário, publicado pela Comissão Estadual Judiciária de Adoção (CEJA) e disponível no site da Corregedoria Geral da Justiça de Mato Grosso (2009), Psicólogos e assistentes sociais possuem muito mais funções nesse cargo. 0 psicólogo, por exemplo, deve proceder à avaliação de crianças e adolescentes elaborando o estudo psicológico a fim de contribuir com a autoridade judiciária no conhecimento dos aspectos psicológicos da vida familiar tanto para o adotado quanto para o adotante; exerce atividades como entrevistas psicológicas, aplicação de testes resultando em um prognóstico; realiza estudo de campo, visitas domiciliares e visitas a abrigos e internatos; faz encaminhamentos à terapia e atendimento especializado; acompanha cada caso avaliando a adaptação criança/família; emite laudos e pareceres; executa o cadastramento de casais interessados em adoção bem como das crianças adotáveis; oferece treinamento de famílias de apoio; promove a prevenção da violência familiar e institucional contra crianças e adolescentes.

Contudo, Silva (2003) aponta que o trabalho do psicólogo varia de acordo com a Comarca em que atua. Em alguns lugares, pode atuar acompanhado do Assistente Social, mas sua função principal é a elaboração de laudos, que são documentos que reúnem conclusões de uma avaliação com o objetivo de estudar o significado psicológico dado ao processo de adoção pelos adotantes.

Já o assistente social, em relação ao Manual de Capacitação supracitado, deve atender as determinações judiciais relacionadas à prática do Serviço Social; realiza a avaliação dos casos elaborando estudo social com a finalidade de contribuir com a autoridade judicial detalhando aspectos socioeconômicos, culturais, interpessoais, familiares, institucionais, comunitários e outros; desenvolver, durante o estudo social, aconselhamento, orientação, encaminhamento e prevenção; aplicar procedimentos técnicos com a família em situação de conflito; acompanhar visita de pais às crianças 
quando determinado pela justiça; realizar trabalhos em conjunto com a equipe interprofissional da Vara da Infância e da Juventude para acrescentar os trabalhos de solicitação de estudo psicossocial. Porém Silva (2003) aponta para ao fato de que a participação de psicólogos e assistentes sociais na Vara da Infância e da Juventude muitas vezes se resume a um parecer inconclusivo que traz informações parciais sobre a estrutura familiar e um diagnóstico situacional.

Diante da importância dessa estruturação de trabalho e de equipe, realizamos o presente estudo no intuito de esclarecer como é o trabalho em uma equipe interprofissional da Vara da Infância e da Juventude em Comarcas do Paraná e demonstrar sua importância em relação aos processos de adoção. Objetiva-se verificar, além da importância do papel da equipe interprofissional no processo de adoção, analisar também o trabalho dos profissionais nesses processos e realizar um comparativo entre os trabalhos realizados em cada Comarca, observando também quais profissionais compõem a equipe. Assim, acredita-se que este estudo possa contribuir para outras produções acadêmicas tanto quanto para elucidar algumas questões importantes no âmbito social, esclarecendo e instigando novas propostas em relação ao trabalho interprofissional no campo da adoção.

\section{Método}

A pesquisa realizada possui uma abordagem qualitativa do tipo descritiva que, de acordo com Campos (2001), busca conhecer e interpretar a realidade sem interferir nesta, descrevendo o que realmente acontece. Segundo esse mesmo autor, a pesquisa qualitativa se baseia em dados coletados nas interações sociais e interpessoais e analisa os dados a partir do significado que os sujeitos atribuem ao fato.

Como instrumento para a coleta de dados, utilizou-se a entrevista semiestruturada que foi escolhida por basear-se apenas em algumas questões previamente formuladas, abertas, ou seja, sem serem estruturadas e precisas, e por não ser necessário usar todas as questões pré-definidas. Além disso, dentro desse modelo, é possível introduzir novas questões de acordo com o andamento da entrevista, como explicita Minayo (1994), o que facilita a obtenção dos dados. Para a realização das entrevistas, foi elaborado e proposto pelas pesquisadoras um Termo de Consentimento, no qual consta a garantia de sigilo, a possível publicação dos dados, o encaminhamento à Clínica Escola de Psicologia da Universidade Estadual do Centro-Oeste, caso necessário, e o fato de as entrevistas serem gravadas.

Outro instrumento, o questionário de formação acadêmico profissional, foi utilizado para levantar dados dos participantes como idade, profissão, formação, etc. Segundo Rey (2005), um questionário não tenta padronizar respostas, mas produzir informações sobre um grupo bem como sobre os sujeitos que o constituem, sendo informações complementares em relação ao que nos interessa conhecer, justificando, assim, o uso de tal instrumento.

0 modelo interpretativo usado foi a análise de conteúdo, pois, como explica Bardin (1977), essa análise é um conjunto de técnicas que visam a analisar as comunicações utilizando procedimentos sistemáticos com o objetivo de descrição do conteúdo das entrevistas. Campos (2001) complementa afirmando que essa análise interpreta os significados dos fenômenos apresentados ao pesquisador, os quais o próprio entrevistado muitas vezes não compreende. Assim, o que se propõe é prestar atenção no que está escondido ou até mesmo subentendido com habilidades de ouvinte e observador e não se deter no superficial, o que é de grande importância nesta pesquisa.

Após ser aprovada pelo Comitê de Ética em Pesquisa com Seres Humanos da Universidade Estadual do Centro-Oeste - Comep/Unicentro - Protocolo n. $10447 / 2008$, a pesquisa foi iniciada contando com a colaboração de três Fóruns do Estado do Paraná, em cidades de médio porte, bem como das equipes interprofissionais do Serviço de Auxílio à Infância (SAI), aqui designadas por equipes A, B e C para garantir o sigilo das mesmas.

\section{Resultados e discussão}

Nas equipes citadas anteriormente, foram entrevistadas as profissionais que no momento a integravam, sendo todas mulheres. Na equipe A, entrevistou-se a Assistente Social I e Psicóloga I; na equipe B, Assistente Social II e Psicóloga II e na equipe C a Assistente Social III. Nesta última equipe, não havia o serviço de Psicologia até o momento da pesquisa. No Quadro 1, são apresentadas as informações das participantes. 
Quadro 1 - Relação dos participantes com os principais dados para elucidar a discussão

\begin{tabular}{|c|c|c|c|c|}
\hline Equipe & Participante & Tempo de Formação & $\begin{array}{l}\text { Possui vínculo com a } \\
\text { instituição/cedida pela } \\
\text { prefeitura }\end{array}$ & Tempo no cargo \\
\hline \multirow[t]{2}{*}{ Equipe A } & Assistente Social I & 25 anos & Efetiva no fórum & 7 meses \\
\hline & Psicóloga I & 16 anos & Cedida pela prefeitura & 1 ano e dois meses \\
\hline \multirow[t]{2}{*}{ Equipe B } & Assistente Social II & 11 anos & Cedida pela prefeitura & 2 meses e meio \\
\hline & Psicóloga II & 6 meses & Efetiva no fórum & 4 meses \\
\hline Equipe C & Assistente Social III & 24 anos & Efetiva no fórum & 22 anos \\
\hline
\end{tabular}

Fonte: Dados da pesquisa.

Esses dados foram obtidos por meio de um questionário de formação acadêmico-profissional previamente estabelecido que se mostrou importante para a pesquisa, uma vez que levantou dados que nos ajudaram a entender melhor o contexto em que este trabalho se realizava. Para a realização das entrevistas e aplicação deste questionário, todas as entrevistadas leram o Termo de Consentimento e assinaram concordando com ele.

Após a transcrição literal e uma leitura inicial das entrevistas, realizou-se uma pré-análise e, a partir desta, organizado um agrupamento dos conteúdos que derivam de cada uma das entrevistas visualizadas globalmente. Do agrupamento, resultaram temáticas que, unidas, tornaram-se três tópicos citados a seguir, definidos a partir de suas particularidades.

Na primeira categoria de análise, o desenvolvimento do processo de adoção, são apresentados alguns tópicos principais como o acompanhamento realizado pelas profissionais aos adolescentes com prática infracional, às famílias, aos processos de adoção dentre outros; e a narrativa do processo de adoção contendo a descrição do trabalho desenvolvido pelas profissionais em um processo de adoção, desde o cadastro dos casais até a união das crianças com estes casais. Na segunda categoria, o funcionamento do trabalho em equipe, a discussão gira em torno da composição da equipe que integra a Vara da Infância e da Juventude e os encontros realizados para reuniões da equipe. Por fim, a última categoria de análise desenvolvida apresenta as percepções sobre o trabalho em equipe, contendo o apoio que os profissionais têm em relação à equipe interdisciplinar bem como a integração do trabalho desta; o rendimento do trabalho em equipe em relação à agilidade dos processos e a melhora do atendimento prestado; e como é o trabalho em equipe, discutindo, neste ponto, o respeito, ou a falta deste, de cada profissional pelos seus conhecimentos e pelos conhecimentos do outro estabelecendo a harmonia da equipe.

\section{Desenvolvimento do processo de adoç̃̃o}

Sendo um processo de extrema importância, a adoção é irrevogável e, segundo Ferreira (2008), requer certo conhecimento da lei, de desenvolvimento humano e emocional bem como experiência no estudo social do caso. Uma das atividades desenvolvidas pela equipe interprofissional é o acompanhamento aos adolescentes, crianças, famílias e abrigos, isso é essencial e relatado pelas profissionais entrevistadas, especificamente pela Psicóloga I que, ao ser questionada sobre suas atribuições no cargo em que ocupava, responde:

... acompanhamento de adolescentes infratores, também fazer perícias né, de famílias, acompanhamento familiar, encaminhamentos técnicos pra necessidades médicas, orientação a professoras em escolas em relação a problemas específicos em cada caso acompanhado, acompanhamento as instituições de apoio nos abrigos ... (Psicóloga I).

Esse trabalho é essencial para o bom desenvolvimento do processo de adoção. 0 acompanhamento feito aos abrigos é de grande importância tanto para 
o processo quanto para as crianças, pois é ali, naquela realidade em que estas últimas se encontram, que o psicólogo ou o assistente social vão perceber as interações das crianças e a qualidade da relação dos irmãos, por exemplo:

... nós temos feito né, algumas muitas vezes a gente vai até a instituição pra observar a criança, fazer o que ela, se é mais participativa na frente dos irmãos, verificar como que eles se dão em ambiente natural porque o abrigo acaba se tornando o ambiente natural dele né. Não tão natural, mas pelo menos o habitual né, lá é a casa deles (Psicóloga II).

A Psicóloga II demonstra, neste trecho, a importância do acompanhamento sem o fórum como pano de fundo. Em outro ambiente, as profissionais conseguem perceber melhor as relações da criança até mesmo para casos em que irmãos são separados no processo de adoção.

No mesmo questionamento, as tarefas que mais se destacaram entre as assistentes sociais das equipes foram entrevistas e visitas domiciliares, pontuando duas das etapas do Estudo Social realizado por elas. Esse estudo é realizado na fase de habilitação do processo, no qual os casais passam a integrar a fila de espera para adoção.

Tão importante quanto essa fase do processo de adoção é o momento preliminar, a preparação das inscrições dos adotantes, o cadastro, bem como a situação do adotado. Paiva (2004) descreve esse processo passo a passo, citando a solicitação de requerimento de adoção, com os documentos necessários em anexo ao requerimento, os estudos sociais e psicossociais que são realizados nessa fase e a efetivação do requerimento. Essa fase é definida por Ferreira (2008) como fase extraprocessual, momento em que se realiza o cadastro dos interessados e a análise da situação da criança ou adolescente. A fase inicial é relatada na fala das profissionais como segue o exemplo:

Porque assim, pra adotar, eles precisam estar em acordo e terem pedido né ou requerido que a gente chama pra eles entrarem na fila de adoção, querem adotar a criança. Então nesse pedido, eles solicitam né, nome tal, endereço, o que faz e falam o perfil da criança que querem adotar. Então aí a característica, o perfil então ele coloca aí. ... Seria Estudo Psicossocial, aí a gente faz essa entrevista e verifica né se este casal realmente né, tem condições né, de adotar uma criança, ... Aí eles entram numa fila né e dependendo do perfil é demorado ou não né ... (Psicóloga II).
Esse momento é crucial, pois, além de gerar uma ansiedade nos adotantes, para dar continuidade e fim ao processo de adoção, é a fase em que a equipe interprofissional investiga características particulares de cada família para definir sua aptidão à adoção. Assim, a atenção é redobrada para que as informações passadas ao juiz sejam as mais claras possíveis para que ele tenha um bom embasamento na hora de decidir por uma adoção.

Depois de concluída a fase da habilitação, a rapidez com que os casais conseguem adotar uma criança dependerá muito das características elencadas pelos adotantes de como querem que seja o adotado, retomando Schweitzer (2009), já citado anteriormente, que afirma que quanto mais características o casal escolhe mais demorado é o processo para ficar com a criança. Uma das entrevistadas, ao referenciar essa demora e à questão das características, apresenta uma explicação pessoal:

Então assim, tem épocas, agora nós estamos na época de nascer meninos. Então temos que observar quem gosta, porque tem muita gente assim, que quer menina. Então assim, quanto mais critérios o casal coloca, tipo assim, quero menina, cor clara, é ..., recém-nascida e que não tenha irmãos. Então assim, quanto mais critérios o casal coloca, mais difícil deles adotarem né. Então, agora tem casais que não aceitam meninos, então vai ficando mais difícil (Assistente Social II).

Pelo alto número de nascimentos de meninos, percebido pela Assistente Social II, ela aponta em sua fala esta "época de nascer meninos" para exemplificar as dificuldades encontradas por vários casais que preferem meninas e, por vezes, acabam aguardando um tempo maior na fila de espera da adoção, acarretando também em uma maior demora no desenvolvimento dos processos. Em outro momento, a Psicóloga I comenta que já percebe mudanças nessa questão, que muitos casais já estão procurando crianças com outros perfis não tão específicos assim.

Quando existe uma criança disponível para adoção com as características requeridas, o processo é finalizado e, nesse ponto, apenas a Psicóloga II e a Assistente Social I se referiram ao processo de adoção em específico. As demais explicaram o processo de habilitação em detalhes.

Então esse casal vem receber a criança, aqui na instituição, das mãos do juiz, e já entra com o pedido de 
adoção. Aí sim é o pedido da adoção propriamente dita tá. Antes ele se habilitou pra adoção, o dia que ele recebe a criança ele entra com o pedido de adoção. Aí ele vai fazer um requerimento e enviar pro juiz solicitando que o nome da criança seja alterado, o nome, filiação, os avós, tudo do casal mesmo tá (Assistente Social I).

Então assim, tendo o casal, tendo a criança né, digamos assim, tendo a criança nós procuramos as características que o casal pede aí nós ligamos pro casal né pra vê se estão interessados. Daí nós mesmos fazemos um requerimento né, um requerimento de adoção, daí eles já ficam com a criança né (Psicóloga II).

Essa fase da adoção é definida por Ferreira (2008) como fase processual, na qual é feita a intervenção técnica que ocorre durante a tramitação do processo de adoção. Assim, a Assistente Social II, após relatar brevemente o processo para adoção até a parte em que os casais entram na fila de espera, passa a descrever também a continuidade deste, quando os casais são chamados para finalizar a adoção. Ou seja, as outras profissionais comentam somente o processo de habilitação para adoção. No processo de adoção, então, ela relata que o casal entra com um requerimento para mudar o registro da criança e, quando a profissional que atendeu o caso apresenta o parecer final constatando que a criança está bem instalada e foi bem recepcionada, conclui-se o processo de adoção.

\section{Funcionamento do trabalho em equipe}

A equipe interprofissional definida anteriormente como atuante, conjunta e prática nos fóruns em casos de adoção, é responsável pelos estudos sociais e psicossociais, que são instrumentos importantes no processo de adoção, como cita Coimbra (2005). Além de avaliar o contexto familiar no qual o adotante será inserido, permite inúmeras possibilidades para mudanças nesse mesmo contexto, a partir de visitas que podem torná-lo mais favorável para o desenvolvimento do adotando. Contudo a intervenção da equipe visa a assessorar a Vara da Infância e da Juventude em qualquer situação que justifique a elaboração de estudo e perícia, ou seja, não somente em casos de adoção como também em processos de destituição de poder familiar (Ferreira, 2008).

A formação da equipe é realizada pelo Poder Judiciário, conforme o Artigo 150 do ECA, Brasil (1990) já citado, e, na maioria das Comarcas entrevistadas, a composição era feita de psicólogos e assistentes sociais como informa a Assistente Social II ao ser questionada sobre quem compõe a equipe interprofissional: "Psicóloga e Assistente Social ... Porque é muito difícil trabalhar sozinha e é muito gostoso trabalhar nessa equipe" (Assistente Social II).

Nessa fala, a entrevistada pontua mais do que a composição da equipe, expressa o fato de ser muito difícil trabalhar sozinha remetendo-se às suas percepções do trabalho em equipe e demonstrando assim a necessidade de um grupo de profissionais para auxiliar o desenvolvimento das atividades tornando esse trabalho mais simplificado. Nesse tema da composição das equipes, somente a Assistente Social III informa que a equipe está incompleta, além de citar outros profissionais: "Atualmente uma Assistente Social, ... e duas comissárias de vigilância. A equipe está desfalcada com a ausência de mais uma Assistente social e de duas Psicólogas" (Assistente Social III).

As comissárias a que a Assistente Social III se refere são profissionais que apresentam nível médio e funcionam como equipe de apoio. Elas não participam diretamente dos processos, mas são de grande importância para auxílio deles, como explica a própria Assistente Social III. Elas não participam de reuniões ou outros encontros específicos, mas auxiliam organizando e separando a documentação necessária.

Sobre as reuniões, as entrevistadas citam que nem sempre é um processo rotineiro com datas definidas, elas são organizadas ou realizadas a partir dos casos que chegam ao Serviço de Auxílio à Infância. Dependendo do caso e da emergência deste, encontros são marcados.

Não, assim uma reunião especificamente pra isso, de modo rotineiro não. Os casos são tratados um a um, conforme a situação, é, não tem muitos casos prontos ao mesmo tempo pra serem tratados (Psicóloga I). ... não existe nada assim pré-estabelecido. Mas sempre há essa ajuda mesmo não tendo essa rotina de encontros né. Mas assim, chegou um caso a gente já liga, chama pra conversa e vê o que pode ser feito. Mesmo que precise ocorrer várias conversas (Assistente Social I).

Esses dois trechos demonstram a importância de reuniões, mesmo sem datas definidas para obterem uma segunda opinião sobre os casos, uma visão diferenciada, já que em alguns momentos as profissionais se detêm mais em um caso ou outro. Costa e Campos (2004) apontam em seu estudo "A Subjetividade Presente no Estudo Psicossocial da 
Adoção", que a decisão dos integrantes da equipe interprofissional não é baseada em critérios pré-estabelecidos por lei justamente por elas não existirem. Constata-se assim a importância de objetivar quais os pontos mais importantes ao determinar qual família está apta ou não a adotar uma criança. E enquanto isso não é feito, as reuniões e encontros são de extrema importância para objetivar as aptidões de uma família adotante. Ainda mais por esse trabalho ser realizado em conjunto pela assistente social e pela psicóloga responsável por cada caso. Na fala da Psicóloga I, ao mencionar quem participa das etapas do processo, afirma que a assistente social é a mesma em todos os casos por haver apenas uma profissional dessa área nesta equipe.

Hum, varia. A Assistente Social é a mesma. A Psicóloga, as Psicólogas são daqueles, dos casos que elas acompanham né. Então eu não tenho acesso, assim a, por uma questão ate de, de, de responsabilidade ética e profissional da equipe, eu só posso responder pelos casos que eu acompanho né... (Psicóloga I).

Diante do exposto, fica evidente a importância do bom funcionamento das equipes e o seu desempenho obtido pois, além de determinarem qual adotante é apto ou não, são elas que percebem todos os movimentos das famílias, fazendo com que os laudos sejam conclusivos nas decisões do juiz no momento de finalizar uma adoção.

\section{Percepcõoes do trabalho em equipe}

A importância da equipe interprofissional não se resume apenas ao trabalho que ela realiza no processo da adoção. A recepção realizada pela equipe faz toda a diferença na confiança e na decisão da família. 0 respeito, o profissionalismo, a educação e a gentileza trazem tranquilidade e segurança para os adotantes, segundo estudo de Costa e Campos (2003).

Essa forma de atendimento e de trabalho realizado pela equipe é resultado direto da relação dessa e das percepções que os integrantes possuem dessa forma de trabalho como exemplifica a Assistente Social III: "Acho enriquecedor trabalhar em uma equipe, pois a qualidade do atendimento prestado é acrescida, tendo em vista que vários enfoques são abordados" (Assistente Social III).

Com essa fala, a Assistente Social III apresenta a importância do trabalho em equipe, o enriquecimento que ela traz ao trabalho como um todo. Cada profissional acrescenta com seu saber e mostra outras formas de atendimento e trabalho em equipe.

Costa e Campos (2004) afirmam, em um de seus estudos, que o olhar técnico do outro é fundamental para a análise das dificuldades encontradas nos processos. Existe essa busca pela afirmação do outro, pela afirmação da equipe que tornaria, na visão do profissional, mais transparente e menos subjetiva a avaliação feita em virtude dos vários olhares e dos diversos embates e diálogos estabelecidos. Assim, a sensação de onipotência de ser alguém juridicamente instituído é minimizada.

Em relação ao exposto, todas as entrevistadas se referiram ao trabalho em equipe de uma forma favorável. Entre outras questões citadas, as referências de que oferece apoio no momento das decisões e que a troca de ideias é essencial, foi apresentada por elas.

eu to gostando, porque assim, são decisões é, mesmo a gente não querendo a gente se envolve, por mais né que a gente cuide, tenha prática e faça terapia, não é assim, a gente não é ileso né (risos), então a equipe é muito bom porque dá muito apoio um pro outro né, porque tem muitas coisas que você não consegue ver e a outra pessoa ela já tá com aquele ... ela sabe do assunto e já fala, "olha você pode ir por aquele caminho" ou às vezes eu falo "oh! Vai por tal caminho" (Psicóloga II).

... eu acredito muito que essa é a melhor forma de se trabalha né. Em conjunto, trocando experiências, trocando as percepções, pra que os profissionais tenham mais clareza sobre, até sobre seu próprio trabalho à medida que expõe pra outras pessoas perceberem. E também pra se ter outras visões sobre o mesmo caso e de outras áreas, então é bem importante (Psicóloga I).

A fala da Psicóloga II, ao citar "... não é assim, a gente não é ileso ...", confirma-se nos estudos de Costa e Campos (2004) ao mencionarem que o profissional deve sempre refletir sobre suas próprias experiências em família e na sua cultura. Alguns casos podem mobilizar os profissionais de tal forma que a possibilidade de mudanças de valores e opiniões é significativa. A terapia, ou até mesmo encontros em equipe, torno o conhecimento do que é material dele e do que é do outro perceptível com mais clareza, causando assim, o desenvolvimento de um trabalho mais condizente.

Nessas falas, percebemos o quanto a troca de ideias auxilia no momento das decisões. Essa forma de trabalho passa mais segurança às profissionais 
em momentos tão importantes, como na elaboração dos laudos. Como resultado desse apoio, muitas entrevistadas relataram que o trabalho em equipe integra os profissionais e faz a soma de saberes acrescentar nas decisões tomadas como cita a Psicóloga I, Psicóloga II e Assistente Social I:

Olha, é um trabalho bem interessante, na medida em que os profissionais, em que todos os profissionais estejam dispostos a trabalhar em conjunto com os outros né. É, a gente enfrenta dificuldades porque nem sempre todos os profissionais estão, estão com essa disposição integral, ainda temos pessoas que trabalham de uma forma fechada no seu próprio círculo de trabalho, no seu próprio espaço (Psicóloga I).

Eu acho que é muito importante principalmente assim, entre a diferença do Psicólogo e do Assistente Social, então tem coisas assim que eu até brinco com a minha colega né, "e aí, vamo pra que lado?" (risos). Porque tem vários programas de assistência social e do governo, aí ela conhece e a gente pede uma luz pra ela né (Psicóloga II).

Aí fica meio que da postura de cada profissional né, porque mesmo entre nós Assistentes Sociais, eu posso ter um parecer e uma colega ter um outro seguimento né. Mas de forma geral a gente sempre consegue discutir e resolve os casos (Assistente Social I).

Apesar da dificuldade citada pela Psicóloga I, percebe-se a importância dessa postura de troca de saberes, o auxílio de outra profissional para resolver e entender os casos que surgem no fórum. Esses saberes em questão, quando efetivamente juntos, acrescentam e clarificam o trabalho realizado. As falas vão ao encontro das afirmações de Dolto (1998) sobre o trabalho em equipe. A autora expõe que o desejável, o possível é que cada profissional aprofunde sua área de saber e aprenda até onde vão os seus limites. Assim, os profissionais devem respeitar o saber do outro e perceber que não é o detentor da razão e que o auxílio de outro saber, de outro profissional em casos como esse de adoção é essencial. Complementando Dolto (1998), Costa e Campos (2004, p. 100) resumem a ideia anterior afirmando que "a horizontalização das relações é fundamental para essa co-construção", ou seja, os conhecimentos devem ser equivalentes e respeitados para um melhor trabalho.

Resultado direto dessa forma de desenvolver as atividades, o rendimento do trabalho também é um fator positivo apontado pelas entrevistadas. Por muitas Comarcas possuírem um volume de processos grande, o auxílio prestado pelos colegas facilita o bom andamento do trabalho realizado com tais processos:

É importante porque a gente tem um volume de trabalho muito grande né, é existem até mesmo habilidades dos Psicólogos que são diferentes então, na verdade a troca de ideias né, a troca de informações entre os profissionais auxilia muito. Até pra reconhecer, "olha to com dificuldade em tal caso" né, auxilia muito trocar ideia, umas vezes até, alguém acompanha mais né do que a outra pessoa né, então acaba dando um, um resultado melhor (Psicóloga II).

Essa troca de ideias, esse apoio e a agilidade, rapidez no andamento dos processos como consequência, são os pontos que mais se destacam nas entrevistas. Isso resulta da resposta dada por muitas profissionais de que gostam de trabalhar em equipe, que é a melhor forma de realizar um bom trabalho nos casos de adoção.

E eu me sinto bem. Eu me sinto parte da equipe, eu gosto muito do meu trabalho. Hoje eu não me vejo voltando pra trabalhar na área da saúde. Porque assim, o trabalho aqui é tão instigante, que ele mexe com você, então eu gosto muito. É uma coisa que me realiza como profissional, trabalhar aqui nessa equipe (Assistente Social II).

Esse gostar de trabalhar em equipe é decorrente da estrutura das atividades de cada comarca. Cada juiz tem autonomia para definir como a equipe irá se organizar para desenvolver suas tarefas, se todos os profissionais irão se unir para resolver o mesmo processo, se isso será dividido e até mesmo quantos processos devem ser analisados de cada vez. Nas três comarcas entrevistadas, cada uma apresentava uma estrutura diferente e na Equipe A, a Assistente Social I já havia trabalhado nessa mesma função em outra comarca e relata que o funcionamento era diferenciado e teve que se adaptar a nova instituição:

Então assim, eu fiz toda uma preparação e um estudo pra me adaptar a estruturação do trabalho daqui né. Mas isso cada juiz tem autonomia né, pra organizar da forma que ele achar melhor o trabalho (Assistente Social I).

Enfim, a equipe interprofissional que trabalha com adoção, antes de tudo, precisa estar sempre disponível e aberta ao diálogo, discussão e supervisão. Como a forma de trabalho se diferencia, cada equipe deve se estruturar da melhor forma possível para atender os adotantes. Devem-se sempre trocar ideias 
e buscar novas bibliografias a fim de obter mais elementos e recursos profissionais para não gerar um isolamento do integrante. Este pode gerar posturas rígidas e a cristalização das atitudes e conhecimentos do profissional, o que é incompatível com a função que exercem nessas equipes (Costa \& Campos, 2004). Essa cristalização é citada por Paiva (2004) como o momento em que o profissional passa a não escutar mais a criança ou o adotante e leva em consideração apenas sua posição e seus possíveis conhecimentos.

Segundo Paiva (2004) e Costa e Campos (2004), as famílias e as crianças também têm muito a ensinar nesse processo e devem ser ouvidas. Cabe aos profissionais não se sentirem donos da verdade absoluta e ampliarem suas vivências para além das experiências profissionais, o que repercutirá em sua vida profissional e pessoal.

\section{Considerações finais}

Este estudo é um dos poucos específicos sobre equipes interprofissionais no processo de adoção. Quando se trata do tema adoção, muitas pesquisas são encontradas falando sobre os processos, a vivência das famílias nesse período e as histórias e experiências das crianças adotadas ou em vias de adoção. Solon (2006), ao fazer um levantamento sobre as últimas pesquisas relacionadas à adoção de crianças e adolescentes, citou vários estudos que apenas mencionam as equipes interdisciplinares, mas não são realizados especificamente sobre elas.

O que podemos concluir desses poucos estudos é que as famílias acreditam e confiam no trabalho realizado pelas equipes interdisciplinares no processo da adoção. Estudos de Costa e Campos (2003) apontam que grande parte das famílias percebe esse trabalho como uma possível constatação de que os adotantes estão no caminho certo; que realmente devem adotar uma criança e que isso os fazem completos. Além do mais, uma boa avaliação significa para os adotantes mais chances de a adoção obter sucesso.

Essa boa avaliação é decorrente de um interprofissionalismo concreto, no qual cada membro realiza seu trabalho com o auxílio de outros integrantes. Nas comarcas entrevistadas, verificou-se que apenas uma delas realiza esse trabalho de forma tão integrada. A equipe B, formada por uma psicóloga e uma assistente social, é a única das três comarcas entrevistadas que aplica o trabalho interprofissional em seu dia a dia, quando discutem cada caso, fazem visitas em conjunto e se reúnem periodicamente para discutir casos mais complexos. As profissionais entrevistadas também afirmam que, mesmo trabalhando em casos separados, antes de enviá-los ao superior, discutem a decisão com todas as integrantes, pois entendem ser uma responsabilidade enorme a decisão que tomam em cada caso.

Nas outras equipes, A e C, o trabalho é mais individualizado, apesar de ocorrerem reuniões para discussão de casos mais complexos. Na equipe C, não havia um profissional de psicologia no momento da entrevista; assim, não podemos afirmar que o trabalho não possui caráter interprofissional, mas, pelos relatos da Assistente Social III, quando havia uma psicóloga trabalhando, eram feitas somente reuniões quando necessário, como na equipe A. Assim, mesmo com reuniões para discussão de casos o trabalho não se caracteriza como interprofissional, segundo definição de Furtado (2007) descrita anteriormente, que aponta ser interprofissional um reagrupamento de conceitos espalhados evitando assim a alienação do trabalho.

Com isso, percebemos que o trabalhado desenvolvido interprofissionalmente na equipe $\mathrm{B}$ é realmente um bom exemplo na medida em que todos os profissionais participam das decisões finais e respondem por todos os casos, aumentando assim as chances de uma boa avaliação dos casais e uma decisão mais apropriada em cada caso. Entende-se que há várias dificuldades para a concretização das atividades desse formato tão integrado, pois o envolvimento entre os profissionais nem sempre ocorre de forma plena, mas apresenta-se como sendo a melhor forma de trabalho nos casos de adoção e a integração deve ser desenvolvida para auxiliar o melhor funcionamento da equipe.

Enfim, a responsabilidade de acerto passada às equipes é alta e, mesmo não conseguindo prever todas as mudanças e novos acontecimentos durante o processo de adoção ou mesmo posteriormente a este processo, essa responsabilidade deve ser compreendida para que as adoções tenham sucesso. Para que isso aconteça, muitas situações ainda devem ser melhoradas, como já vem ocorrendo com as novas mudanças nas leis da adoção e a criação do Cadastro Nacional da Adoção, o que está facilitando o processo ${ }^{1}$. Apesar de o trabalho

1 Graças ao fato das novas leis de adoção serem implantadas concomitante, a pesquisa é que as referências feitas a esta foram poucas ou quase nulas. 
ser diferenciado em várias comarcas, o medo, a ansiedade, as dúvidas e incertezas sempre irão aparecer e não somente os integrantes da equipe interprofissional estão implicados nisso como também os juízes, promotores e outros profissionais que atuam nesses casos, pois a subjetividade que envolve a adoção é ampla e a atuação dessas equipes auxiliando os adotantes é de grande importância e deve ser reconhecida por todos.

\section{Referências}

Bandeira, M. (2001). Adoção na prática forense. Ilhéus: Editus.

Bardin, L. (1977). Análise de conteúdo. Lisboa: Edições 70.

Brasil. Ministério da Saúde. (1990). Estatuto da Criança e do Adolescente (3. ed.). Brasília: Ministério da Saúde.

Campos, L. F. de L. (2001). Métodos e técnicas de pesquisa em psicologia. Campinas: Alínea.

Campos, N. M. V., \& Costa, L. F. (2003). A avaliação psicossocial no contexto da adoção: Vivências das famílias adotantes. Psicologia: Teoria e Pesquisa, 19(3), 221-230.

Campos, N. M. V., \& Costa, L. F. (2004). A subjetividade presente no estudo psicossocial da adoção. Psicologia: Reflexão e Crítica, 17(1), 95-104.

Coimbra, J. C. (2005). A demanda nos processos de habilitação para adoção e a função dos dispositivos judiciais. Estudos e Pesquisas em Psicologia, 5(2), 67-78.

Corregedoria geral da justiça de Mato Grosso. (2009). Manual de capacitação para psicólogos e assistentes sociais. Recuperado em 15 out. 2009, em http:// www.tj.mt.gov.br/cgj/Pagina.aspx?IDConteudo=1014
Dolto, F. (1998). Destinos de crianças: Adoção, família de acolhimento, trabalho social (E. Brandão, Trad.). São Paulo: M. Fontes.

Ferreira, L. A. M. (2008). Aspectos jurídicos da intervenção social e psicológica no processo de adoção. Recuperado em 18 out. 2009, em http://www. justitia.com.br/artigos/y57czc.pdf

Furtado, J. P. (2007). Equipes de referência: Arranjo institucional para potencializar a colaboração entre disciplinas e profissões. Interface - Comunic, Saúde, Educ, 11(22), 239-255.

Minayo, M. C. S. (Org.). (1994). Pesquisa social: Teoria, método e criatividade. Petrópolis: Vozes.

Paiva, L. D. (2004). Adoção: Significados e possibilidades. São Paulo: Casa do Psicólogo.

Rey, F. G. (2002). Pesquisa qualitativa em psicologia: Caminhos e desafios. São Paulo: Pioneira Thomson Learning.

Schweitzer, F. (2009). Adoção, infância e juventude. Recuperado em 17 out. 2009, em http://portal.tjpr. jus.br/web/adocao_inf_juv/adocao_nacional

Silva, D. M. P. (2003). Psicologia jurídica no processo civil brasileiro: A interface da psicologia com direitos nas questões de família e infância. São Paulo: Casa do Psicólogo.

Solon, L. de A. G. (2006). Adoção nas pesquisas. In L. de A. G. Solon. A perspectiva da criança sobre seu processo de adoção. Dissertação de Mestrado, Faculdade de Filosofia, Ciências e Letras de Ribeirão Preto, Universidade de São Paulo, São Paulo.

Wald, A. (1988). Direito de família (6. ed.). São Paulo: Revista dos Tribunais. 